\title{
Ultrasonographic Assessment of the Fasting Gallbladder Volume in Healthy Adults in Calabar; Correlation with Body Weight
}

\author{
Akintomide A. $\mathrm{O}^{1}$, Eduwem D.U. ${ }^{1}$ \\ ${ }^{1,1}$ Radiology Department, University Of Calabar Teaching Hospital.
}

\begin{abstract}
The size of the gallbladder varies between the fed and fasting states. In healthy adults, it is said to vary with age, gender, body size indices and diet. There is also a noticeable variation from country to country. A prospective study of 141 consecutive healthy adult, aged eighteen years and above was carried out. They were weighed and then scanned with a 2 dimensional (2D) ultrasound machine after eight to twelve hours of fast to determine their fasting gallbladder volume ( $F G B V)$. The subjects were grouped into four weight categories with a range of 20kilograms $(\mathrm{kg})$ and the mean fasting gallbladder volume for each group was calculated. The variation in volume with body weight was assessed and a positive correlation was observed. The overall mean $F G B V$ is $27.7+/-12.3 \mathrm{~cm}^{3}$
\end{abstract}

Keywords: Adults, Body weight, Fasting gallbladder volume, Ultrasonography.

\section{Introduction}

The gallbladder stores and concentrates bile produced by the liver. It releases it in response to food ingestion to aid in fat digestion. The size of the gallbladder varies in an individual between the fed and fasting states [1]. It is examined sonographically in the fasting state to allow adequate distension with bile for proper visualization of the lumen and walls. The fasting gallbladder volume is the volume of the lumen after eight to twelve hours of nil per oral.

The fasting gallbladder volume is increased in the state of pregnancy [2]. It is also increased in pathological conditions like cholelithiasis, primary sclerosing cholangitis, primary biliary cirrhosis and noninsulin dependent diabetes mellitus $[3,4,5]$.

Ultrasonography (US) is a non-ionizing, non-invasive, readily available and relatively cheap imaging technique. It has become the modality of choice for the routine examination of the gallbladder in the last two decades. Ultrasonography provides an accurate method of assessing the gallbladder. Mclntosh et al found an accuracy rate of $98.9 \%$ when they reviewed and correlated the sonographic and surgical findings in patients who underwent cholecystectomy [6]. This high rate of accuracy is influenced by adequate patient preparation of nil per oral for eight to twelve hours to allow full distension with bile. Water ingestion [7] and intravenous (IV) contrast agents [8] have been shown to cause gallbladder contraction, so if IV contrast examination is simultaneously requested for, the ultrasound scan (USS) should be carried out first. There are several 2D ultrasonographic methods of computing the gallbladder volume [9]. Researchers have individual preferences for these methods $[10,11,12]$.

From the studies carried out in different parts of the world, variation were found the normal mean fasting gallbladder volume (FGBV) in adults. It is therefore imperative to find the normal mean value in our environment. This will help to alert the clinicians concerning the apparently healthy subjects who are discovered to have higher values than expected for our environment. They are prone to cholelithiasis, since an increase in fasting gallbladder volume and reduced motility have been implicated in lithogenesis. We also seek to establish the variation (if any) of the fasting gallbladder volume with body weight as it has been observed in our clinical practise that patients with normal hepatobiliary system of same age, do have different values.

\section{Subjects and Method}

Approval for the study was obtained from the research and ethics committee of the hospital. It was a prospective study of 141 consecutive healthy males and female adults, eighteen years and above.

Inclusion criteria:

i. Normal consenting individuals without hepatobiliary or abdominal symptoms.

ii. Clients for routine ultrasound check-up.

Exclusion criteria:

i. Known biliary or liver disease.

ii. Pregnancy.

iii. Diabetes mellitus.

iv. History of pancreatitis.

v. Sickle cell disease. 
vi. Ascites.

An informed consent is obtained and the subject's gender, age and weight were documented. They are scanned after eight to twelve hours of fast with a $2 \mathrm{D}$ ultrasound machine using a $3.5 \mathrm{MHz}$ curvilinear transducer. The liver and pancreas are scanned rule out pathologies and the stomach to confirm compliance to the nil per oral instruction.

The length of the gallbladder is obtained in the longitudinal scanning plane [Fig. 1], while the width [Fig.2] and height are gotten in transverse plane [Fig. 3]. The volume of the fasting gallbladder is then computed by the machine from these three dimensions. The subjects were grouped into four categories according to their weight, with a range of $20 \mathrm{~kg}$ within each group. The mean fasting gallbladder volume was then calculated for each weight category.

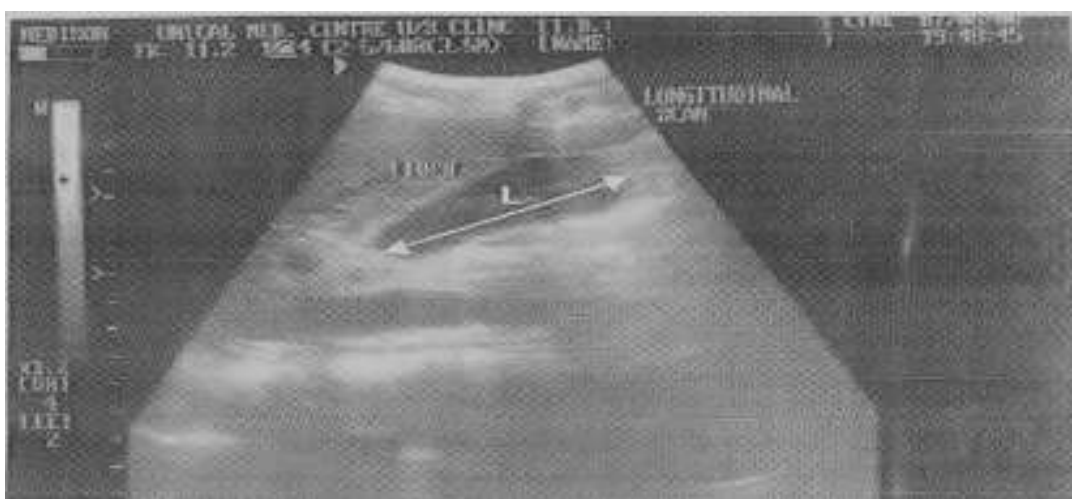

Figure 1. Longitudinal scan of gallbladder showing the maximum length (L)

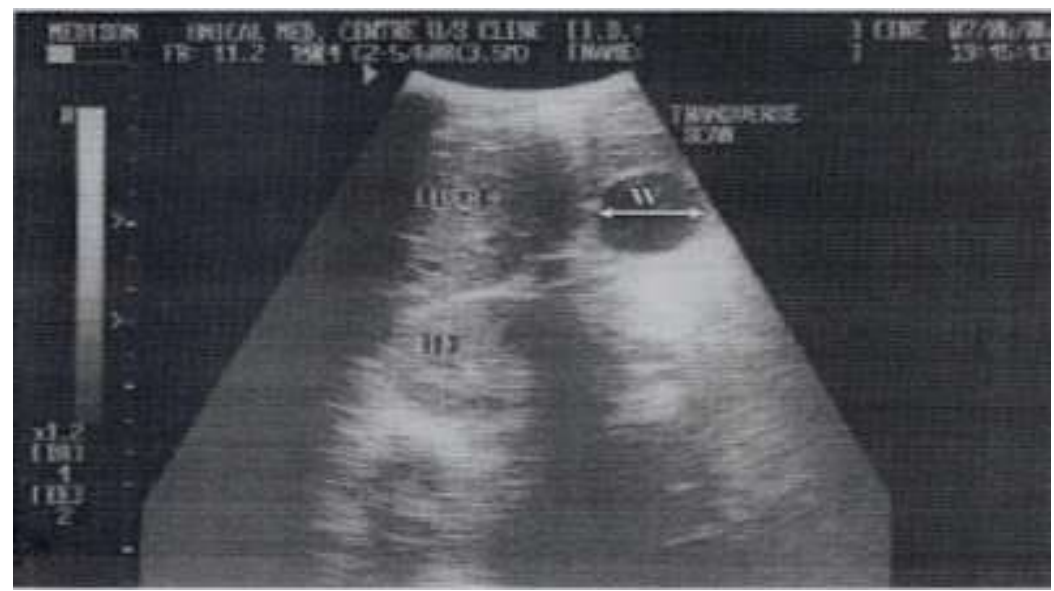

Figure 2. Transverse scan of gallbladder showing the widest transverse diameter-Width (W)

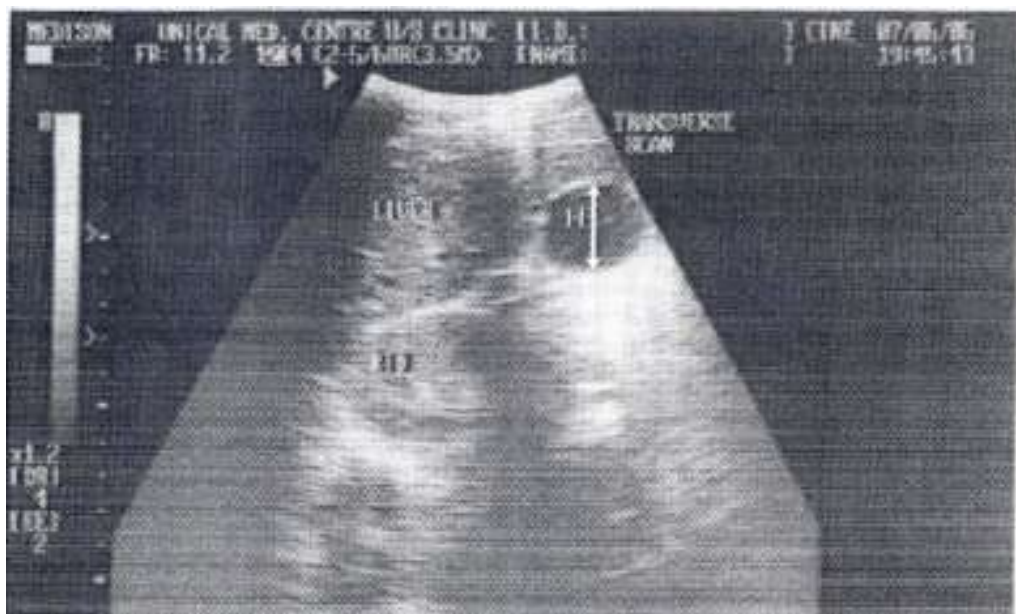

Figure 3. Transverse scan of gallbladder showing the maximum height $(\mathrm{H})$ 


\section{Results}

There were 141 subjects, 63 males and 78 females [Figure 4]. The age range of the subjects is 19 to $76 y e a r s$ and that of the weight is between 39 to $115 \mathrm{~kg}$. Table 1 shows the different weight categories and their mean fasting gallbladder volume.

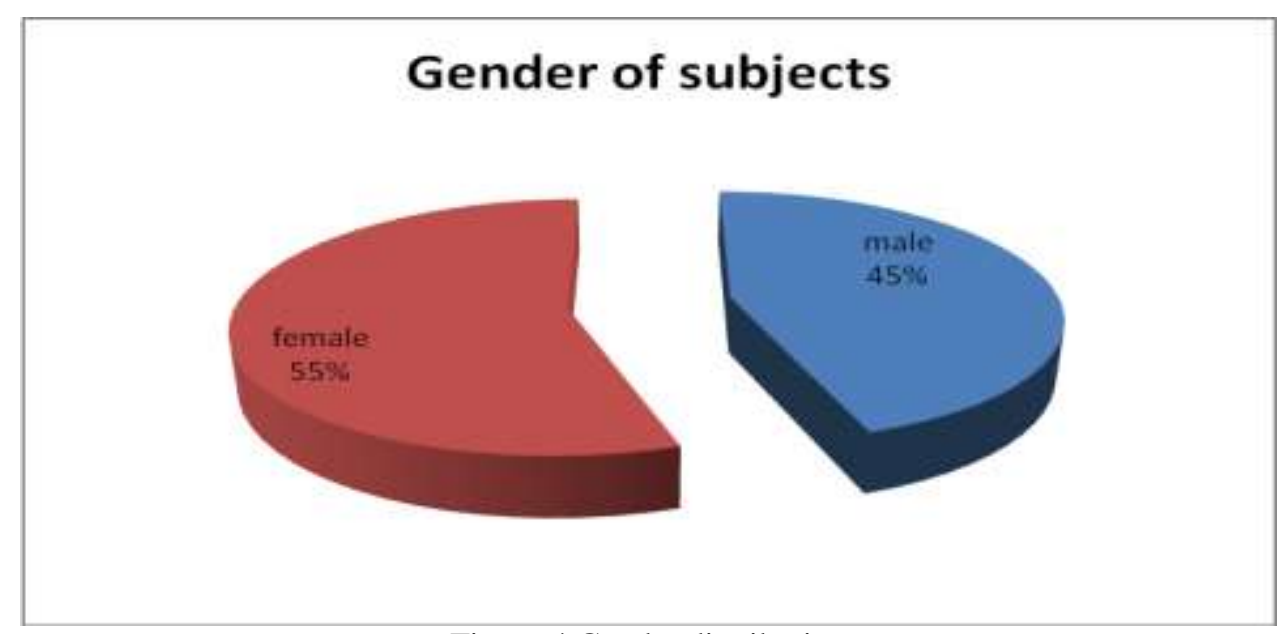

Figure 4.Gender distribution

Table 1. Fasting Gallbladder Volume Vs Body Weight

\begin{tabular}{llr}
\hline Body weight $(\mathrm{kg})$ & Frequency & FGBV $\left(\mathrm{cm}^{3}\right)$ \\
\hline $36-55$ & 30 & 23 \\
$56-75$ & 71 & 27.6 \\
$76-95$ & 19 & 30.9 \\
$96-115$ & 3 & 36.1 \\
\hline
\end{tabular}

\section{Discussion}

The overall mean FGBV in our study is $27.7+/-12.3 \mathrm{~cm}^{3}$. This is higher than values gotten in Greece $\left(22+/-7 \mathrm{~cm}^{3}\right)$ [3] and italy (males $=18.7+/-0.2 \mathrm{~cm}^{3}$ and females $\left.17.0+/-0.3 \mathrm{~cm}^{3}\right)$ [12] but lower than that obtained by Idris $\left(33 \mathrm{~cm}^{3}\right)$ in southwest Nigeria. Diet might be a contributory factor to the higher values obtained in both regions of Nigeria because the average Nigerian eats a low protein diet. In the study by perreard et al, the FGBV is significantly increased while the the plasma cholecystokinin level is reduced with low fat, low protein diet [13].

Our study examined the relationship between body weight and FGBV without considering the subject's age, height or body mass index (BMI) and it revealed a positive correlation with body weight. This same observation was made in other studies $[3,12,14,15]$. The higher value we got in males was supported by Guliter et al [4] and Palasciano et al [12]. The former also observed that the FGBV varies significantly only between gender and not with age.

\section{Conclusion}

The mean fasting gallbladder volume increases with body weight. It value also varies in different parts of the world and it is higher in Nigerians than most of the western world were similar studies have been done.

\section{References}

[1] S. Ryan, M. McNicholas and S.J. Eustace Anatomy for diagnostic imaging, (2nd Ed). 5 (Toronto: W.B Saunders Company Ltd., 2004), pp. 179.

[2] A.A Van Bodegraven, C.J. Bohmer, R.A. Manoliu et al., Gallbladder contents and fasting gallbladder volumes during and after pregnancy, Scandinavian Journal of Gastroenterology, 33(9), 1998, 993 - -997.

[3] N.C. Gourtsoyiannis, J.E. Damilakis, N.Z. Charoulakis, A.S. Bakautaki, J.G. Viahonikolis, E. Xynos. Relationship of gallbladder contour, fasting volume and emptying to body size indices in normal subject and patients with gallstones. Digestion. 1995; 56(5): 395 -399 .

[4] S. Guliter, S. Yimazs, T. Karakan. Evaluation of gallbladder volume and motility in non-insulin dependent D.M patient using real time ultrasound. J Clin Gastroenterol 2003 Oct; 37(4): $288-91$.

[5] P.C Van de Meeberg, P. Portincasa, F.H Wolfhagen et al. Increased gallbladder volume in primary sclerosing cholangitis. Gut 1996 Oct; 39(4): $594-9$. 
[6] D.M. Mclntosh, H.F. Penny. Gray scale ultrasound as a screening procedure in the detection of gallbladder disease. Radiology.1980 Sept; 136(3): $725-7$.

[7] R. Starinsky, Z. Alon. Gallbladder size: Is it affected by the oral intake of water or dilute contrast medium. J Med. 1994 Jun; 13(6): $435-8$.

[8] H. Nazaroglu, C. Akgul, Y. Bukte, A. Bilici, M. Simsek. Volume Changes in the gallbladder in association with various radiological examination. J. Clin USS. 2005 Jun; 33(5): $214-7$.

[9] K. Romanski. Methods of estimating gallbladder volume. Wiad Lek. 2006;59(1 -2): 140 - 5 (ISSN: 0043 - 5147)

[10] W.J. Dodds, W.J. Groh, R.M.A. Darweesh et al. Sonographic measurement of gallbladder volume. AJR AmJ. Roentgenol.1985 Nov; 145(5): $1009-11$.

[11] I.B. Andersen, H. Monrad, S. Gronvall, L. Hojgard. In vitro and In vivo accuracy of sonographic gallbladder volume determinations. J. Clin Ultrasound. 1993 Mar - Apr; 21(3): $157-62$.

[12] S Hashimoto, H Goto. An evaluation of 3D ultrasonography for the measurement of gallbladder volume. AmJ. Gastroenterol.1999 Dec; 94(12): $3492-6$.

[13] M. Perreard, N. Iconomidis, C. Bernard, J. Chayvialle, A. Gerlami. Effect of a low-fat diet on the fasting volume and postprandial emptying of the gallbladder. Gastroenterol Clin Biol. 1993:17(6 - 7): 435 - 40.

\section{INFORMED CONSENT}

I am DR. AKINTOMIDE A. O.

Hy research project is on: ULTRASONOGRAPHIC ASSESSMENT

OFFASTING; GAI.LBI.ADDER VOLUME IN NORMAL ADUITS IN

\section{CAI.ABAR, NIGERIA.}

\section{WHAT IS THE STUDY ABOUT?}

1. The gallbladder is an organ in the abdomen that assists in digestion of lat.

2. The listing galtbladder volume (volume when you have not waten for 8 to 12 hours) can be increased or decreased by several conditions.

3. Lltrasound measurement of the fasting gallbladder volume will not be painful and will not cause any damage to your body.

4. I:xamination of or extension of examination to the upper abdomen is not lime consuming and is at no extra cost to you.

5. This rescarch project is to find out the fasting gallbladder volume in normat adults in Calabar and to see how this volume is affected by body dimensions, including body weight and height.

6. This nomal volume will be used in our clinical practice to know when there is a probtem with the gallbladder.

7. You will be identified with a code number instead of your name.

8. Your participation in this research is at your own freewill.

9. Retusal to participate will not affect your normal investigation and treatment.

Thank you. 


\section{INFORMED CONSENT FORM}
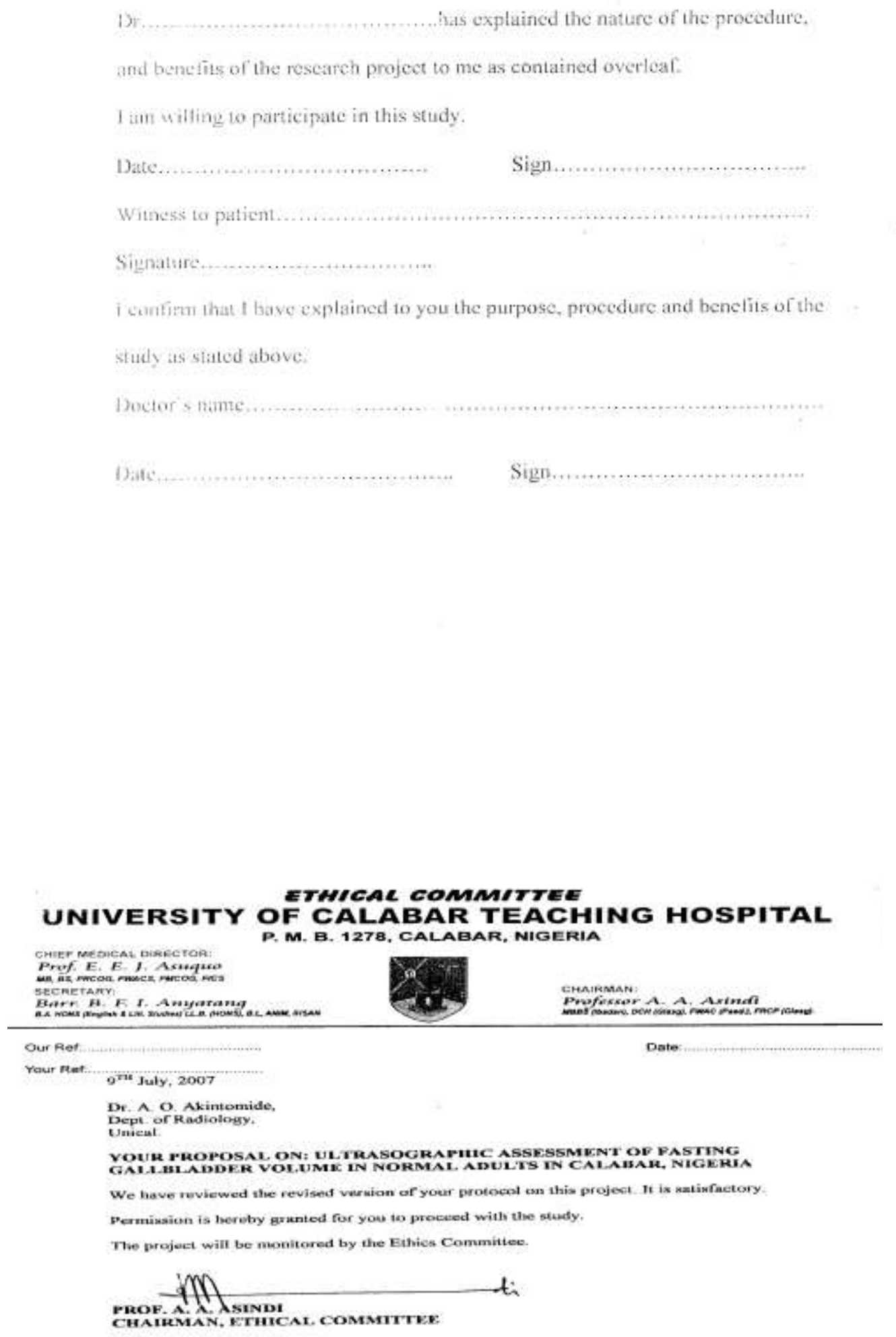